\title{
Uma Concepção Pós-Moderna do Princípio da Legalidade Administrativa à Luz da Teoria da Legislação Simbólica e da Necessidade de Concretização de Direitos Fundamentais
}

\author{
RAFAEL DA SILVA SANTIAGO
}

Advogado, Graduado em Direito pela Universidade de Brasília - UnB.

\author{
Submissão:29.09.2012
}

Decisão Editorial: 30.10 .2012

RESUMO: 0 estudo busca ampliar os argumentos para a consolidação de uma concepção pós-moderna do princípio da legalidade administrativa. Com base na constitucionalização do direito administrativo e na sua relação com os direitos fundamentais, será comprovada, pela teoria da legislação simbólica, a insuficiência da visão tradicional desse princípio frente à hipertrofia (i) do seu simbolismo e (ii) do simbolismo dos direitos fundamentais. Assim, perceber-se-á a necessidade de uma nova legalidade, assentada na vinculação direta da Administração à Constituição e ao Direito, combatendo a prevalência de seu caráter simbólico e do caráter simbólico dos direitos fundamentais, viabilizando a sua adequada concretização.

PALAVRAS-CHAVE: Legalidade administrativa pós-moderna; legislação simbólica; direitos fundamentais.

ABSTRACT: The study intends to extend the arguments for the consolidation of a postmodern conception of the principle of legality in the administrative regime. Based on the constitutionalisation of Administrative Law and in its relation with fundamental rights, the insufficiency of the traditional view of this principle will be justified by the theory of symbolic legislation, in view of the hypertrophy of its symbolism and of the symbolism of fundamental rights. Thus it will be demonstrated the need of a new legality, based on the direct linkage of the Public Administration to the Constitution and Law, fighting against the prevalence of its symbolism and of the symbolic character of fundamental rights, enabling their proper realization.

KEYWORDS: Postmodern administrative legality; symbolic legislation; fundamental rights.

SUMÁRIO: Introdução; 10 regime jurídico-administrativo, constitucionalização do direito administrativo e o princípio da legalidade; 1.1 Conteúdo tradicional do princípio da legalidade; 1.2 Conteúdo pós-moderno do princípio da legalidade; 2 Direitos fundamentais como elementos determinantes para uma nova legalidade administrativa; 3 A lei e os direitos fundamentais no regime jurídico-administrativo e a teoria da legislação simbólica; 3.1 Legislação simbólica; 3.1.1 Legislação simbólica 
no regime jurídico-administrativo; 3.2 Constitucionalização simbólica; 3.2.1 Combate à hipertrofia da função simbólica dos direitos fundamentais; Conclusão; Referências.

\section{INTRODUÇÃO}

O princípio da legalidade é uma das mais importantes normas jurídicas do direito administrativo. Sua observância é obrigatória quando da realização do agir administrativo, de modo que os seus efeitos alcançam praticamente todos os atos produzidos pela Administração Pública, condicionando a manifestação da vontade estatal à estrita observância da manifestação da vontade geral, isto é, da lei.

Com isso, em face da visão tradicional do referido princípio, o administrador apenas pode atuar caso haja autorização ou determinação em lei, o que resulta na conclusão de que a atividade administrativa consistiria na tão só execução dos comandos legalmente estabelecidos, submetendo-se e vinculando-se diretamente à lei.

Entretanto, desde o surgimento da legalidade administrativa como princípio no regime de Direito Público, a sociedade, o Estado e o próprio Direito foram alvos de diversas modificações, que tiveram como consequência a necessidade de uma reconstrução de seus fundamentos e de seus elementos, em virtude, sobretudo, do período da pós-modernidade ${ }^{1}$.

Cumpre atentar que as aludidas modificações alcançaram todos os ramos do Direito, incluindo o direito administrativo. Inserido nesse período de modificações, inclusive, é possível identificar o fenômeno da constitucionalização do Direito Administrativo como protagonista na construção de uma nova forma de atuar por parte da Administração Pública.

De um modo mais específico, a consolidação da força normativa da Constituição - que passa a ser o diploma unificador do sistema e fundamento de validade para todo o regime jurídico-administrativo - e a consagração dos direitos fundamentais como fundamento de legitimidade do Estado Democrático de Direito levam à necessidade da reconstrução de paradigmas clássicos do aludido regime, entre os quais a visão tradicional do princípio da legalidade.

Isso porque, em um cenário social de grande complexidade e pluralidade, o Direito Administrativo não pode admitir uma paralisia da atuação do Estado em nome da constante e fracassada necessidade de lei para viabilizá-la,

1 Quanto ao sentido de "pós-modernidade" utilizado no trabalho, vale destacar que, nos termos dos ensinamentos do Professor Eduardo Carlos Bianca Bittar, "[...] a expressão é polêmica e não gera unanimidades, assim como seu uso não somente é contestado como também se associa a diversas reações ou a concepções divergentes [...]" (BITTAR, Eduardo Carlos Bianca. O direito na pós-modernidade. Revista Sequência, n. 57, p. 131-152, dez. 2008). A par de toda essa discussão, aqui se mostra suficiente a utilização da primeira característica da pós-modernidade, que é a impossibilidade de gerar consensos. Em suma, traduz uma sociedade contemporânea objeto e protagonista de um processo de transformações. 
a despeito da existência de autorização em outras normas jurídicas como a própria Constituição.

Nesse contexto, ciente da grande divergência doutrinária em torno do conteúdo do referido princípio no direito administrativo contemporâneo, o objetivo do trabalho se assenta em uma ampliação do leque argumentativo voltado à consolidação de sua concepção pós-moderna, a partir da aplicação da teoria da legislação simbólica no regime de Direito Público.

Sendo assim, à luz da aludida teoria, faz-se mister realizar um estudo sobre a influência do conteúdo tradicional do princípio da legalidade administrativa no fenômeno de hipertrofia de sua função simbólica enquanto norma jurídica e da prevalência do caráter simbólico dos direitos fundamentais, que prejudicam o desempenho das atividades necessárias à satisfação dos interesses coletivos, ampliando-se os argumentos no sentido de legitimar uma nova legalidade no âmbito do regime jurídico-administrativo.

\section{REGIME JURÍDICO-ADMINISTRATIVO, CONSTITUCIONALIZAÇÃO DO DIREITO ADMINISTRATIVO E O PRINCÍPIO DA LEGALIDADE}

De início, vale mencionar que o regime jurídico-administrativo, também chamado de regime de Direito Público, nada mais é do que o conjunto de princípios e regras que disciplinam a atuação da Administração Pública quando em posição de superioridade perante os administrados, tanto na satisfação do interesse público quanto na concretização de direitos fundamentais (o que, regra geral $^{2}$, não deixa de representar a satisfação do interesse público).

A partir dessa visão, dois aspectos pertinentes ao regime jurídico-administrativo devem ser devidamente abordados, como premissa indispensável para o entendimento da construção argumentativa - fundada na teoria da legislação simbólica - capaz de conferir maior legitimidade ao novo conteúdo da legalidade administrativa, adequando-a aos anseios da sociedade pós-moderna ${ }^{3}$.

Primeiramente, o direito administrativo, após a Segunda Guerra Mundial, vem deixando de lado a sua concepção associada à continuidade e à estabilidade das instituições para adotar uma postura de mudança e de questionamento

2 Nem sempre a concretização de direitos fundamentais representa a satisfação de interesses públicos. Pelo contrário, existem casos em que a sua satisfação se realiza pela não concretização daqueles direitos, como, p. ex., nos casos de aplicação do princípio da reserva do possível. Para uma leitura aprofundada a esse respeito, vale mencionar a obra: KELBERT, Fabiana Okchstein. Reserva do possível e a efetividade dos direitos sociais no direito brasileiro. Porto Alegre: Livraria do Advogado, 2011.

3 De acordo com Marçal Justen Filho, "[...] a expressão direito administrativo pós-moderno indica a necessidade de tomar em vista as alterações sociais, econômicas e políticas contemporâneas. Mais precisamente, trata-se de admitir a impossibilidade de compreender a realidade contemporânea [...] a partir de conceitos e fórmulas elaboradas para explicar e compreender o Estado e o Direito de cem anos atrás" (JUSTEN FILHO, Marçal. Curso de direito administrativo. 7. ed. Belo Horizonte: Fórum, 2011. p. 78). 
de paradigmas clássicos. Essa é uma consequência direta do movimento de constitucionalização do direito administrativo ${ }^{4}$.

Nesse cenário de fortalecimento da Constituição no regime jurídico-administrativo, o Professor Gustavo Binenbojm preconiza que:

Na tarefa de desconstrução dos velhos paradigmas e proposição de novos, a tessitura constitucional assume papel condutor determinante, funcionando como diretriz normativa legitimadora das novas categorias. A premissa básica a ser assumida é a de que as feições jurídicas da Administração Pública [...] estão alicerçadas na própria estrutura da Constituição, entendida em sua dimensão material o estatuto básico do sistema de direitos fundamentais e da democracia. ${ }^{5}$ (grifo nosso)

Na seara desse movimento de constitucionalização do direito administrativo, cumpre destacar o primeiro aspecto relevante do regime jurídico-administrativo contemporâneo, cuja menção se mostra imprescindível para o presente trabalho: a grande influência da teoria dos direitos fundamentais em sua percepção.

Nesse momento, é importante observar que a Constituição emerge como o elemento que guia a superação das categorias jurídicas tradicionais do direito administrativo, "[...] mediante a adoção do sistema de direitos fundamentais e do sistema democrático qual vetores axiológicos - traduzidos em princípios e regras constitucionais - a pautar a atuação da Administração Pública [...]"6.

Por sua vez, o segundo aspecto do regime de Direito Público, cujo destaque se mostra obrigatório, relaciona-se com a sua identificação como um conjunto de regras e de princípios enquanto verdadeiras normas jurídicas, dotados, pois, de força normativa, sendo capazes de solucionar diretamente os conflitos que envolvam a Administração Pública.

Não há nenhuma novidade quanto à força normativa das regras de direito. Por outro lado, se anteriormente era atribuída, ao princípio, a função abstrata de orientação da ordem jurídica, hoje se percebe a possibilidade de sua densificação no caso concreto, vez que os princípios, à luz da concepção pós-positivista do direito, passam a ser dotados de normatividade?

Dessa forma, os princípios exercem função normativa extremamente relevante no regime de Direito Público, sendo possível afirmar, inclusive, que essas normas jurídicas desempenham influência mais expressiva no direito admi-

4 BARROSO, Luis Roberto. Neoconstitucionalismo e constitucionalização do direito: o triunfo tardio do direito constitucional no Brasil. Revista da Escola Nacional da Magistratura, Brasília, n. 2, p. 26-72, out. 2006.

5 BINENBOJM, Gustavo. A constitucionalização do direito administrativo no Brasil: um inventário de avanços e retrocessos. Revista Eletrônica sobre a Reforma do Estado (RERE), Salvador: Instituto Brasileiro de Direito Público, n. 13, p. 8, mar./abr./maio 2008. Disponível em: <http://www.direitodoestado.com.br/rere.asp>. Acesso em: 3 ago. 2012.

6 Idem, p. 7

7 BARROSO, Luis Roberto. Op. cit., p. 30. 
nistrativo do que no direito privado ${ }^{8}$, em especial como resultado da ausência de codificação das suas regras no Brasil.

Feitas essas considerações a respeito do movimento de constitucionalização do direito administrativo - propulsor da especial importância dos direitos fundamentais no Direito Público - e das suas normas jurídicas - a partir da identificação da força normativa dos princípios -, será realizada a análise de um dos mais importantes princípios que regem a atuação da Administração Pública: o princípio da legalidade.

\subsection{Conteúdo tradicIONAL do PRINCÍPIO dA LEGALIDADE}

À luz da perspectiva tradicional - que, como se observará, enseja a prevalência da função simbólica dos direitos fundamentais, obstaculizando a sua plena e efetiva concretização - o princípio da legalidade assume a característica de diretriz básica da atuação dos agentes da administração. Assim, toda e qualquer atividade administrativa deveria ser autorizada por lei. Caso contrário, a atividade é ilícita9.

Celso Antônio Bandeira de Mello, a partir da premissa da submissão do Estado à lei, resume de maneira precisa essa concepção do princípio da legalidade, afirmando ser ele "[...] a consagração da ideia de que a Administração Pública só pode ser exercida na conformidade da lei e que, de conseguinte, a atividade administrativa é atividade sublegal, infralegal, consistente na expedição de comandos complementares à lei"10.

No âmbito do direito administrativo, a doutrina costuma admitir a existência de dois princípios da legalidade. O primeiro está inserido no art. 5을. II da Constituição, e é apresentado como a legalidade do setor privado. A partir de suas orientações, o particular não pode ser obrigado a fazer ou a deixar de fazer alguma coisa, salvo em virtude de lei ${ }^{11}$.

Por sua vez, a segunda acepção do princípio da legalidade consistiria na legalidade administrativa, que é tão somente mencionada pelo caput do art. 37 da Lex Fundamentalis. Quanto à visão tradicional, o Professor Lucas Rocha Furtado ensina que:

[...] a legalidade administrativa, denominada de legalidade restrita, ou estrita, cria a situação de que a Administração Pública somente pode agir se e quando a lei autorizar a atuação. De acordo com essa interpretação dominante, ainda que a

8 JUSTEN FILHO, Marçal. Op. cit., p. 109.

9 CARVALHO FILHO, José dos Santos. Manual de direito administrativo. 25. ed. São Paulo: Atlas, 2012. p. 19.

10 MELLO, Celso Antônio Bandeira de. Curso de direito administrativo. 27. ed. São Paulo: Malheiros, 2010. p. 100.

11 FURTADO, Lucas Rocha. Curso de direito administrativo. 3. ed. Belo Horizonte: Fórum, 2012. p. 83. 
atividade estatal não importe em impor qualquer conduta positiva ou negativa de qualquer cidadão, a administração estaria impedida de agir. ${ }^{12}$

Como se pode perceber, a visão tradicional do princípio da legalidade não leva em consideração a própria força normativa da Lex Fundamentalis, vez que essa representaria apenas um fundamento remoto da atuação do administrador, porquanto sirva de fundamento imediato para a lei que autoriza ou determina o desempenho da atividade administrativa. Por isso, a consolidação de uma visão pós-moderna do aludido princípio é a medida que se impõe.

\subsection{ConteÚdo Pós-MODERNo do PRINCíPIO dA LEGALIDADE}

A visão pós-moderna do princípio da legalidade parte da premissa, bem ressaltada pelo Professor Lucas Rocha Furtado, do equívoco de se exigir que "[...] cada programa de governo, que cada ato praticado ou atividade desenvolvida tenham sido detalhadamente disciplinados por meio de lei [...]"13.

Isso porque a permanência da legalidade administrativa em sua perspectiva tradicional como paradigma do direito administrativo implica uma verdadeira paralisia da atuação do Estado, tendo em vista a necessidade de uma regra específica para cada conduta de seus agentes ${ }^{14}$, o que, por si só, demonstra a prevalência do caráter simbólico do princípio da legalidade tradicional enquanto norma jurídica.

Além disso, vale salientar que as transformações havidas no Estado moderno, desde o surgimento do Estado-providência até a sua crise, ocorrida nas últimas décadas do século XX, bem como o nascimento do Estado Democrático de Direito, "[...] agravaram o descompasso entre as velhas categorias e as reais necessidades e expectativas das sociedades contemporâneas em relação à Administração Pública"15.

Sendo assim, torna-se imprescindível uma expansão do conteúdo da legalidade, de modo que a atividade administrativa não se restrinja a fazer o que a lei determine ou autorize, mas seja compatível com todas as normas jurídicas. Assim, a atuação da Administração se mostra legítima e necessária não quando lei a autorize ou determine, mas quando não proibida pelo direito, ou seja, por todas as normas jurídicas, porque em conformidade com elas.

Diante dessa constatação e a partir do movimento de constitucionalização do direito administrativo, a Lex Fundamentalis, seus princípios e o próprio sistema de direitos fundamentais devem ser o centro da unidade de todo o regime de Direito Público. Com efeito, o paradigma adequado para esse regime se

12 Idem, ibidem.

13 Idem, p. 84.

14 FERRAZ, Luciano. Direito administrativo. In: MOTTA, Carlos Pinto Coelho. Curso prático de direito administrativo. 3. ed. Belo Horizonte, 2011. p. 1-31.

15 BINENBOJM, Gustavo. Op. cit., p. 6. 
baseia na Constituição como fundamento primeiro da atuação administrativa, configuradora de verdadeiras competências administrativas ${ }^{16}$.

Nesse sentido, o Professor Gustavo Binenbojm ensina que:

Toda sistematização dos poderes e deveres da Administração Pública passa a ser traçada a partir dos lineamentos constitucionais pertinentes, com especial ênfase no sistema de direitos fundamentais e nas normas estruturantes do regime democrático, à vista de sua posição axiológica central e fundante no contexto do Estado Democrático de Direito. ${ }^{17}$

Esse é o cerne da mudança de perspectiva do princípio da legalidade, a qual se mostra mais adequada pelo fato de expandir a possibilidade de atuação da Administração Pública à proporção do aumento das necessidades da coletividade, cuja satisfação se dá, em regra, pela própria Administração, como decorrência de imposição constitucional.

Em resumo, a mudança de perspectiva da legalidade administrativa significa que os atos da Administração, em havendo competência constitucional, vez que a Constituição passa a ser o fundamento primeiro da atuação administrativa: (i) devem estar diretamente vinculados a todo o Direito, especialmente em conformidade com os princípios e regras da Lex Fundamentalis, diploma unificador de todo o sistema; e (ii) podem ser praticados quando não proibido pelas normas jurídicas.

A partir dessa concepção, cumpre salientar que, no âmbito da esfera normativa aplicável ao administrado, não se defende a supressão da garantia da legalidade e da estrita observância da lei, desde que essas estejam em harmonia com os princípios, regras e valores estabelecidos na Constituição.

Destarte, o Professor Gustavo Binenbojm preconiza, de maneira brilhante, que:

[...] a atividade administrativa continua a realizar-se, via de regra, (i) segundo a lei, quando esta for constitucional (atividade secundum legem), (ii) mas pode encontrar fundamento direto na Constituição, independente ou para além da lei (atividade praeter legem), ou, eventualmente, (iii) legitimar-se perante o direito, ainda que contra a lei, porém com fulcro numa ponderação da legalidade com outros princípios constitucionais (atividade contra legem mas com fundamento numa otimizadora aplicação da Constituição). ${ }^{18}$ (grifo nosso)

Cumpre atentar que, como principal resultado da concepção pós-moderna da legalidade administrativa, tem-se um significativo aumento das garantias do administrado. Isso porque, além de atuar em conformidade com a ordem jurídica, a administração poderá concretizar de maneira mais adequada os seus 
direitos, notadamente aqueles que tenham natureza constitucional, pois o agir administrativo é legítimo sempre que não proibido pelas normas jurídicas, sob o fundamento de uma competência estabelecida na Lex Fundamentalis.

Ressalte-se, inclusive, a existência de orientação do Supremo Tribunal Federal - STF no sentido de que a prática de atos administrativos normativos vinculados diretamente à Constituição será admitida em certas situações, ainda que inexista lei regulando o agir administrativo ${ }^{19}$.

Nesse sentido, Marçal Justen Filho observa que:

[...] ao julgar a Ação Declaratória de Constitucionalidade no 12 , o STF considerou válida a Resolução $\mathrm{n}^{\mathbf{0}} 7$ do Conselho Nacional de Justiça, que impusera vedação ao nepotismo no Poder Judiciário. O STF reputou que a omissão do legislador não constitui obstáculo à edição de normas regulamentares destinadas a tornar efetivas determinações constitucionais. ${ }^{20}$ (grifo nosso)

Ademais, vale assinalar que essa mudança de abordagem decorre, sobretudo, da ideia de que a perspectiva instrumental do direito positivo, orientada pelo pressuposto de que as leis constituem meios insuperáveis para se alcançar certos fins almejados pelo legislador, tem como resultado um modelo funcional simplista e ilusório ${ }^{21}$.

Deve-se mencionar a existência de um relevante número de leis que têm a única função de codificar juridicamente normas sociais reconhecidas. Além disso, a complexidade do ambiente social dos sistemas jurídico e político se mostra demasiadamente acentuada para que a atuação do Estado, por intermédio da legislação, possa ser qualificada como mecanismo seguro de controle social $^{22}$.

Essa é, inclusive, uma das orientações do pós-positivismo, que procura ir além da legalidade estrita, mas sem, no entanto, desprezar o direito posto, bem como empreender uma abordagem moral do direito, não recorrendo a categorias metafísicas ${ }^{23}$, constatações que alcançam diretamente o regime jurídico-administrativo.

Nesse sentido, face à insuficiência da lei como norma reguladora de todas as situações da sociedade, a interpretação e aplicação da ordem jurídica devem se inspirar por uma teoria de justiça, mas que não abarque voluntarismos ou personalismos ${ }^{24}$.

9 JUSTEN FILHO, Marçal. Op. cit., p. 202.

0 Idem, p. 202-203.

21 NEVES, Marcelo. A constitucionalização simbólica. 3. ed. São Paulo: WMF Martins Fontes, 2011. p. 29.

22 Idem, ibidem.

23 BARROSO, Luis Roberto. Op. cit., p. 30.

24 Idem, ibidem. 
Essas e outras exigências da sociedade pós-moderna só podem ser devidamente satisfeitas pela Administração Pública caso os seus paradigmas clássicos passem por profundas transformações, que tenham como consequência, entre outras, uma mudança de perspectiva no conteúdo do princípio da legalidade administrativa, a partir da referida abordagem de vinculação direta da atuação do administrador à Constituição e ao Direito.

\section{DIREITOS FUNDAMENTAIS COMO ELEMENTOS DETERMINANTES PARA UMA NOVA LEGALIDADE ADMINISTRATIVA}

Um estudo contemporâneo do Direito Administrativo só pode ter como ponto de partida a constatação de que a vinculação primeira e mais relevante da Administração Pública se refere aos direitos fundamentais, "[...] expressão jurídica máxima da dignidade da pessoa humana" ${ }^{\prime 25}$. Assim, faz-se mister assinalar a centralidade dos direitos fundamentais como elemento determinante para uma mudança no entendimento da legalidade administrativa.

De início, cumpre destacar a definição de Direito Administrativo oferecida por Marçal Justen Filho, que o identifica como um conjunto de normas jurídicas de direito público que "[...] disciplinam as atividades administrativas necessárias à realização dos direitos fundamentais [...]"26, bem como regulam a organização das composições estatais e não estatais incumbidas da execução dessas atividades.

Destarte, os direitos fundamentais assumem importância central no desempenho da função administrativa, que deixa de ser apenas uma função que o Estado ou alguém em seu nome exerce na intimidade de uma organização e regime hierárquicos ${ }^{27}$, porquanto é acrescentada, ao seu conteúdo, a necessidade de realização dos direitos fundamentais.

Esse caráter central dos direitos fundamentais deriva de um certo consenso contemporâneo sobre o seu papel - exercido em conjunto com a democracia - de fundamento de legitimidade e elemento constitutivo do Estado Democrático de Direito, que propaga sua influência por toda a Administração Pública e teoria do direito administrativo ${ }^{28}$.

Isso significa que qualquer discussão a respeito do que é, para que serve e qual a origem da autoridade do Estado e do Direito encontra, na atualidade, resposta nas relações entre a sistemática dos direitos fundamentais e a sistemática da democracia. Nada mais óbvio, vez que da conjugação desses dois elementos surge o Estado Democrático de Direito, organizado como o conjunto de

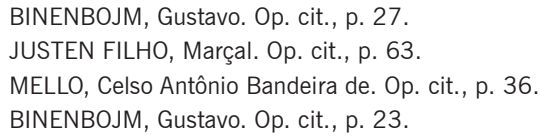


instituições políticas e jurídicas arquitetadas sob o fundamento e com o objetivo de proteger e promover a dignidade da pessoa humana ${ }^{29}$.

A Lex Fundamentalis é o mecanismo por meio do qual os sistemas democráticos e de direitos fundamentais se institucionalizam na seara do Estado ${ }^{30}$. Nesse sentido, em um contexto de constitucionalização do direito administrativo, "[...] deve ser a Constituição, seus princípios e especialmente seu sistema de direitos fundamentais, o elo de unidade a costurar todo o arcabouço normativo que compõe o regime jurídico administrativo [...]"31.

Esse raciocínio se impõe pelo fato de o direito administrativo estar vinculado à concretização dos direitos fundamentais, definidos, sobretudo, a partir dos preceitos da dignidade da pessoa humana.

Nesse sentido, Marçal Justen Filho assevera que essa vinculação se manifesta por intermédio de duas vertentes ${ }^{32}$.

De um turno, o Direito Administrativo regula um setor de atividades e um conjunto de estruturas estatais e não estatais com o objetivo de produzir a limitação dos poderes que se relacionam com a existência do Estado e com o desenvolvimento da comunidade humana ${ }^{33}$.

Assim, o referido Direito visa impedir que a concentração de poderes políticos e econômicos, os quais decorrem da própria atividade de satisfação de interesses coletivos, implique o sacrifício da liberdade e de outros postulados fundamentais. Isso significa que, sob essa vertente, o direito administrativo é um instrumento de limitação do poder estatal e não estata ${ }^{34}$, que tem, como principal objetivo, resguardar direitos fundamentais, consubstanciando, por isso, a orientação negativa da atuação da Administração Pública.

Por outro lado, no que se refere à sua segunda vertente de vinculação, o direito administrativo deve se preocupar com a realização dos interesses coletivos e com a manifestação permanente dos valores fundamentais. Com efeito, torna-se um instrumento jurídico e social para a promoção e concretização desses valores. Essa é a orientação positiva ${ }^{35}$ da atuação da administração, tendente, pois, a concretizar direitos fundamentais.

A partir dessa constatação, Marçal Justen Filho ensina que:

É fundamental eliminar o preconceito de que as organizações estatais possuem justificativas de existência em si mesmas. O Estado não existe para satisfazer as suas estruturas burocráticas internas nem para realizar interesses exclusivos de al-

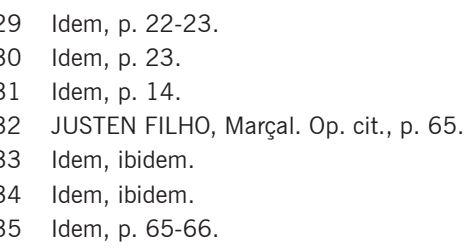


guma classe dominante [...]. O direito administrativo - e o Estado [...] - somente se justifica como instrumento para a realização dos direitos fundamentais, entre os quais avulta de importância a dignidade humana. (grifo nosso)

Essa qualidade da administração de instituição realizadora de direitos fundamentais é tão evidente na ordem jurídica contemporânea que toda atividade interpretativa-aplicativa do administrador deve ser desempenhada em sintonia e com vistas à maior concretização possível dos direitos fundamentais, face à sua centralidade e seu relevo axiológico ${ }^{36}$.

\section{A LEI E OS DIREITOS FUNDAMENTAIS NO REGIME JURÍDICO-ADMINISTRATIVO E A TEORIA DA LEGISLAÇÃO SIMBÓLICA}

A legislação simbólica refere-se à hipertrofia da função simbólica da atividade legiferante e de seu produto, isto é, da lei, especialmente em detrimento de sua função jurídico-instrumenta ${ }^{37}$.

Marcelo Neves explica, então, que:

[...] Considerando-se que a atividade legiferante constitui um momento de confluência concentrada entre sistemas político e jurídico, pode-se definir a legislação simbólica como produção de textos cuja referência manifesta à realidade é normativo-jurídica, mas que serve, primária e hipertroficamente, a finalidades políticas de caráter não especificamente normativo-jurídico. ${ }^{38}$

Nesse cenário, o fracasso da função instrumental da lei não é resultado, apenas, da ineficácia das normas jurídicas, sendo necessário o debate acerca da sua função simbólica. Vale ressaltar que uma grande quantidade de leis exerce funções sociais latentes em contradição com sua eficácia normativo-jurídica, isto é, contrariando sua concepção jurídica manifesta. "[...] Não se trata, portanto, de uma simples negação da legislação instrumental [...]."139

Especificamente quanto ao regime de Direito Público, viu-se que as categorias jurídicas do direito administrativo vêm sofrendo uma série de transformações, com o objetivo de se adequar aos anseios e necessidades da sociedade pós-moderna. Entre essas transformações, constatou-se a mudança no entendimento da legalidade administrativa.

Com o objetivo de se conferir maiores argumentos para a consolidação do conteúdo pós-moderno do princípio da legalidade, faz-se necessário analisar sua aplicação por intermédio da ótica da teoria da legislação simbólica, construindo-se, assim, uma maior legitimidade para a mencionada mudança

BINENBOJM, Gustavo. Op. cit., p. 30.

NEVES, Marcelo. Op. cit., p. 23.

Idem, p. 30.

9 Idem, ibidem. 
de perspectiva, bem como mais motivos para o enfraquecimento da concepção tradicional dessa norma jurídica.

Nesse sentido, as leis oriundas de atos de legislação instrumental podem, ao longo do tempo, adquirir natureza predominantemente simbólica, por intermédio de um movimento em que o sentido político da lei e da atividade legiferante prevalece hipertroficamente sobre o seu aparente sentido normativo-jurídico ${ }^{40}$.

É possível perceber que, no direito administrativo, sob a perspectiva tradicional de vinculação direta e imediata da atuação administrativa à lei, o princípio da legalidade enquanto norma jurídica vem se inserindo, cada vez mais, em um movimento de hipertrofia de sua função simbólica.

Ressalte-se que esse contexto impede o exercício de competências administrativas previstas na Lex Fundamentalis e, em especial, a concretização de direitos fundamentais, os quais também são alvo de um processo de fortalecimento do simbolismo em sua constitucionalização, em virtude da vinculação rígida da atuação estatal determinada pelo conteúdo tradicional da legalidade.

Nesse sentido, não são poucas as situações em que a Administração Pública se mostra incapaz de realizar as suas competências constitucionais alegando, para tanto, a inexistência de lei autorizando ou determinando a sua atuação, o que, por si só, coloca em risco a eficácia imediata dos direitos fundamentais.

Sendo assim, faz-se mister identificar como esse movimento e a sua aplicação ao regime jurídico-administrativo contribuem para uma mudança no conteúdo do princípio da legalidade, que esteja adequada à pós-modernidade, como forma de combate ao simbolismo dessa norma jurídica e dos próprios direitos fundamentais.

\subsection{LEGIILAÇÃo SIMBÓLICA}

De acordo com os ensinamentos de Harald Kindermann ${ }^{41}$, o conteúdo de legislação simbólica pode ser: (i) confirmar valores sociais; (ii) demonstrar a capacidade de ação do Estado e (iii) adiar a solução de conflitos sociais por meio de compromissos dilatórios.

O conteúdo de confirmação dos valores sociais surge a partir de um contexto em que se exige, rotineiramente, do legislador uma posição acerca dos conflitos sociais fundados em valores. Nesse ambiente, os grupos que se colocam nos debates pela prevalência de certos valores enxergam a transformação de seus valores em lei como uma forma de reconhecimento da superioridade

40 Idem, p. 30-31.

41 KINDERMANN, Harald. Symbolische Gesetzgebung. In: NEVES, Marcelo. Op. cit., p. 32. 
social de sua compreensão valorativa, tornando-se secundária a eficácia normativa da mencionada $1 \mathrm{ei}^{42}$.

Em outras palavras, pode-se afirmar que o atendimento das expectativas do grupo que obteve a vitória legislativa é realizado com a tão só produção do ato legislativo, sendo irrelevantes os seus efeitos instrumentais. Com isso, percebe-se um fenômeno de confirmação simbólica de pretensões normativas, deixando-se de lado a imposição efetiva dessas pretensões ${ }^{43}$.

À luz desse aspecto de confirmação de valores sociais, a legislação simbólica tem sido utilizada, basicamente, como mecanismo para diferenciação de grupos e dos respectivos valores ou interesses, em um movimento de fortificação ou enfraquecimento de um grupo em oposição a outros no âmbito da sociedade ${ }^{44}$.

Por sua vez, sob a perspectiva da demonstração da capacidade de ação do Estado, a legislação simbólica tem como objetivo fortalecer a confiança dos indivíduos nos sistemas político e jurídico. Assim, Marcelo Neves explica que:

[...] o legislador, muitas vezes sob pressão direta do público, elabora diplomas normativos para satisfazer as expectativas dos cidadãos, sem que com isso haja o mínimo de condições de efetivação das respectivas normas. A essa atitude refere-se Kindermann com a expressão "legislação-álibi". Através dela o legislador procura descarregar-se de pressões políticas ou apresentar o Estado como sensível às exigências e expectativas dos cidadãos. ${ }^{45}$

Com efeito, os membros do parlamento e do governo se apresentam como atuantes, garantindo que o Estado-legislador permaneça como merecedor da confiança dos indivíduos ${ }^{46}$.

Além disso, a legislação-álibi é identificada também nas situações em que existe uma insatisfação popular diante de certos acontecimentos ou da emergência de problemas sociais, de modo que é exigida do Estado, com muita frequência, uma reação imediata ${ }^{47}$.

Nesses casos, ainda que, via de regra, não seja provável que a produção normativa possa colaborar para a solução dos aludidos problemas, o comportamento legiferante traduz um verdadeiro álibi do legislador em face da população que demandava uma reação do Estado. No entanto, ressalta-se que, não obstante a criação de novas leis, sob a perspectiva instrumental, o problema social permanece fora do controle estatal ${ }^{48}$.

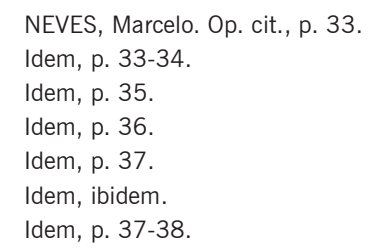


Ademais, a legislação-álibi se manifesta não só como reação às pressões sociais ou como apontamento na prestação de contas à sociedade e ao eleitorado, mas também como instrumento de apresentação simbólica das instituições. Nesse caso, trata-se de uma verdadeira exposição abstrata do Estado como instituição digna da confiança pública ${ }^{49}$.

Qualquer que seja a sua vertente, a legislação-álibi provém da tentativa de dar a aparência de solução dos problemas sociais ou, pelo menos, da ambição de persuadir a sociedade das boas intenções do legislador. Entretanto, ela não só deixa os problemas sem solução como também impede que eles sejam devidamente resolvidos ${ }^{50}$.

Analisando os objetivos da legislação-álibi, Marcelo Neves aponta que esse movimento procura:

[...] criar a imagem de um Estado que responde normativamente aos problemas reais da sociedade, embora as respectivas relações sociais não sejam realmente normatizadas de maneira consequente conforme o respectivo texto legal. Nesse sentido, pode-se afirmar que a legislação-álibi constitui uma forma de manipulação ou de ilusão que imuniza o sistema político contra outras alternativas, desempenhando uma função "ideológica". ${ }^{51}$

Nesse sentido, a legislação-álibi tem o condão de introduzir um sentimento de bem-estar na sociedade. Contudo, vale ressaltar que ela nem sempre consegue o sucesso em sua função simbólica. Isso porque quanto maior a sua utilização, ela falhará com maior constância, porquanto o emprego excessivo da legislação-álibi gera a descrença no próprio ordenamento jurídico ${ }^{52}$.

Por fim, a legislação simbólica também pode servir para procrastinar a solução de conflitos sociais por intermédio de compromissos dilatórios, de modo que as divergências entre grupos políticos não são resolvidas pelo ato legislativo. A lei, inclusive, é aprovada de maneira consensual pelas partes envolvidas justamente em virtude de sua ineficácia. Assim, o acordo entre os grupos políticos não se fundamenta no conteúdo do ato normativo, mas, sim, no adiamento da solução do conflito para um futuro indeterminado ${ }^{53}$.

Com isso, sob essa perspectiva, um conflito político de uma sociedade pode ser arrefecido por intermédio de uma lei aparentemente progressista, que satisfaça os grupos divergentes, mas que resulta na transferência da solução do conflito social para um futuro indeterminado ${ }^{54}$.

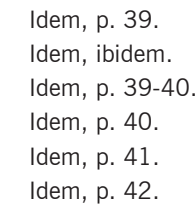




\subsubsection{Legislação simbólica no regime jurídico-administrativo}

Prima facie, cumpre ressaltar que se utiliza a teoria da legislação simbólica para fundamentar a insuficiência da legalidade administrativa enquanto norma jurídica. Ou seja, sustenta-se, como motivo para uma mudança de abordagem, o predomínio do simbolismo da norma jurídica presente no regime de Direito Público que estabelece que o administrador só pode atuar quando autorizado ou determinado em lei.

Sendo assim, fica claro que a construção argumentativa lastreada na legislação simbólica não tem como destinatária a lei produzida pelo Estado- legislador para, sob a ótica tradicional do princípio da legalidade, possibilitar a atuação do Estado-administrador. Expande-se, pois, o leque argumentativo para embasar a prevalência do simbolismo presente na norma jurídica relativa à legalidade administrativa.

Com efeito, à luz da função simbólica das legislações, os argumentos construídos para uma mudança de perspectiva na legalidade administrativa se referem ao seu próprio conteúdo. Trata-se, portanto, de uma expansão da teoria da legislação simbólica, alcançando não só as regras de direito, mas também os princípios, porque dotados de força normativa e de função simbólica.

Caso se restrinja a utilização da teoria da legislação simbólica apenas às leis, tem-se, como outro caminho para sustentar a sua aplicação ao princípio da legalidade, o desenvolvimento argumentativo voltado para o seu entendimento não como princípio, mas como regra de direito positivada pela atividade legiferante do constituinte originário no caput do art. 37 da Lex Fundamentalis.

Assim, na medida em que a legalidade é o resultado de uma atividade política, protagonizada pelo constituinte, com objetivos jurídicos ${ }^{55}$, ela pode ser muito bem analisada sob a ótica de seu simbolismo, isto é, abordando-se a hipertrofia de suas finalidades políticas de natureza não especificamente normativo-jurídica. Trata-se, nada mais, de abordar a constitucionalização simbólica movimento que decorre da legislação simbólica - da legalidade administrativa.

Passadas essas considerações iniciais sobre a aplicabilidade da aludida teoria, é importante observar a hipertrofia da função simbólica do princípio da legalidade sob a ótica tradicional. Essa observação é comprovada pela simples constatação do aumento da complexidade do agir administrativo em face: (i) da consolidação do Estado Democrático de Direito, (ii) da necessidade de realização de direitos fundamentais, (iii) da diversificação dos interesses coletivos e das necessidades da sociedade, etc.

55 Nesse sentido, Celso Antônio Bandeira de Mello ensina que: "Para avaliar corretamente o princípio da legalidade e captar-Ihe o sentido profundo cumpre atentar para o fato de que ele é a tradução jurídica de um propósito político: o de submeter os exercentes do poder em concreto - administrativo - a um quadro normativo que embargue favoritismos, perseguições e desmandos" (MELLO, 2010, p. 100). 
No mundo contemporâneo, o tradicional princípio da legalidade é alvo de um perigoso fortalecimento de seu simbolismo, que, além de impedir o desempenho de competências estabelecidas na Constituição - muitas delas relacionadas à concretização de direitos fundamentais - engessa sobremaneira o agir administrativo, em nome de uma expectativa simbólica de que todas as ingerências pessoais, políticas e ideológicas do administrador serão afastadas pela lei.

Atualmente, é possível perceber a hipertrofia dessa expectativa simbólica em detrimento da sua efetividade. Cumpre atentar que não se pode negar a importância desse simbolismo no conteúdo do princípio da legalidade. No entanto, ele não pode sobrepor-se à função jurídico-instrumental da própria Administração Pública, obstaculizando o desempenho de suas competências delineadas na Lex Fundamentalis.

Isso significa que não se pode admitir a hipertrofia desse simbolismo, que traz como resultado a insuficiência do agir administrativo perante as necessidades da coletividade e os direitos fundamentais.

É importante o reconhecimento da função simbólica do princípio da legalidade no sentido de se contrapor a quaisquer tendências de exacerbação personalista dos governantes e de se opor a todas as formas de poder autoritário, como verdadeiro remédio natural contra o poder monocrático ou oligárquico ${ }^{56}$.

No entanto, essa função simbólica não pode sobrepor-se às próprias finalidades da Administração Pública, inviabilizando a realização de direitos fundamentais, vez que os anseios da sociedade não se conformam com a visão tradicional de natureza simplista do princípio da legalidade e da atuação administrativa.

Mesmo porque a aludida função simbólica não é suficiente para o real afastamento de tendências personalistas e autoritárias do agir administrativo. Pelo contrário, ela só será devidamente satisfeita nos casos em que haja uma vinculação direta da atuação estatal à Constituição, diploma que reúne a função simbólica, as regras e os princípios relacionados tanto ao afastamento de tendências personalistas e autoritárias do administrador, quanto à necessária concretização de direitos fundamentais, de forma que o caso concreto irá demonstrar qual orientação deverá prevalecer.

Partindo-se para uma análise do conteúdo tradicional do princípio da legalidade comparado ao conteúdo da legislação simbólica exposto por Harald Kindermann, tem-se que essa norma jurídica vem servindo para confirmar valores sociais, por intermédio da consecução das expectativas de afastamento de tendências pessoais e autoritárias das atividades estatais, tornando-se irrelevantes os seus efeitos instrumentais. 
Desse modo, identifica-se um movimento de confirmação simbólica de pretensões no sentido de limitar o poder estatal a qualquer custo, sem levar em consideração a efetividade dessas pretensões, pois a legalidade administrativa, por si só, não é capaz de frear os impulsos pessoais, políticos, ideológicos e autoritários de certos agentes públicos.

No entanto, a partir da crença absoluta no conteúdo tradicional do aludido princípio, promove-se uma hipertrofia do simbolismo existente na pretensão de controle do poder estatal por meio da lei, ainda que essa pretensão não se concretize de maneira efetiva na realidade da administração. Pelo contrário, ela inviabiliza o exercício de suas competências.

Portanto, além de não frear de maneira efetiva os anseios pessoais e autoritários dos administradores, a hipertrofia da função simbólica do conteúdo tradicional do princípio da legalidade impede até mesmo a concretização de direitos fundamentais, vez que obstaculiza o exercício de competências constitucionais.

Contudo, tanto simbolismo transparece para a sociedade uma crença de confiança nos sistemas político e jurídico - mais uma característica da teoria da legislação simbólica - mesmo porque a visão tradicional da legalidade configuraria um escudo intransponível contra a subjetividade e o autoritarismo no agir administrativo. Mas a realidade vem demonstrando a insuficiência desse raciocínio.

Vale salientar que a confiança de que a produção de uma lei é capaz de solucionar os problemas sociais decorrentes dos abusos de poderes cometidos pelos administradores é válida e importante, mas se torna insuficiente em um contexto de necessária e permanente concretização de direitos.

A experiência vem demonstrando que as orientações clássicas da legalidade, isto é, o papel clássico exercido pela lei no direito administrativo, não vem obtendo sucesso na solução de problemas sociais decorrentes da subjetividade e do autoritarismo na conduta dos administradores.

Pelo contrário, costuma-se perceber que a legalidade não é - e nunca foi - um escudo absoluto de proteção do interesse público, capaz de sujeitar os anseios, favoritismos, simpatias e todos os sentimentos de ordem pessoal, política ou ideológica à lei.

Ainda que por meio da submissão direta e estrita do administrador à lei não seja possível a solução dos aludidos problemas, o conteúdo tradicional da legalidade administrativa traduz um verdadeiro álibi da Administração Pública em face da sociedade, que demanda uma conduta impessoal e proporcional do Estado. No entanto, não obstante a vinculação direta do agir administrativo às leis, sob a perspectiva instrumental, o problema do autoritarismo, das simpatias, da pessoalidade permanece fora do controle estatal. 
Desse modo, a partir da falsa crença clássica na lei como instrumento capaz de resolver os problemas estatais, introduz-se um sentimento de bem-estar na sociedade, o que significa a existência de uma verdadeira função ideológica de resolução - mas apenas aparente - de tensões. Assim, os membros da administração se apresentam como verdadeiros "agentes da lei", garantindo que o Estado permaneça merecedor da confiança da sociedade.

No entanto, a concepção tradicional da legalidade administrativa, decorrente da tentativa de dar a aparência de solução dos problemas sociais ou da pretensão de convencer a sociedade das boas intenções do legislador, deixa os problemas sem solução e, o mais grave, impede que eles sejam resolvidos, vez que limita a atividade do administrador à simples atuação infralegal, insuficiente diante da constante necessidade de concretização de direitos fundamentais por parte do Estado.

Nesse sentido, a partir da utilização da função simbólica do conteúdo tradicional do princípio da legalidade de submissão completa da Administração Pública às leis, que supostamente afastaria qualquer pretensão pessoal ou autoritária, constrói-se uma forma de manipulação que imuniza o sistema político contra outras alternativas, sob o argumento falacioso, propugnado por autores consagrados, como Celso Antônio Bandeira de Mello, de que a "[...] Administração Pública só pode ser exercida na conformidade da lei [...]"57.

É óbvio que o administrador não pode atuar sem a existência de qualquer limite. Mas esse limite não pode consistir em um óbice para as suas principais atividades, entre elas a concretização de direitos fundamentais. Por isso, uma perspectiva pós-moderna do princípio da legalidade, que vincule o administrador à Constituição - e não apenas à lei - parece ser a mais adequada.

\subsection{Consitiucionalzação SIMBólica}

Prima facie, Marcelo Neves se utiliza do conceito de Constituição como fator e produto da distinção funcional entre direito e política como subsistemas da sociedade para identificar o constitucionalismo como o processo por meio do qual essa distinção é realizada. Tudo à luz da perspectiva de Luhman de que a Lex Fundamentalis traduz um acoplamento estrutural entre política e Direito ${ }^{58}$.

Nesse contexto, Marcelo Neves ensina que: "[...] a Constituição em sentido especificamente moderno apresenta-se como uma via de 'prestações' recíprocas e, sobretudo, como mecanismo de interpenetração [...] entre dois sistemas sociais autônomos, a política e o Direito" ${ }^{\prime \prime}$.

57 Idem, ibidem.

58 NEVES, Marcelo. Op. cit., p. 65.

59 Idem, p. 65-66. 
Tendo como ponto de partida a tipologia da legislação simbólica já tratada anteriormente ${ }^{60}$, o aludido autor afirma que a constitucionalização simbólica também se manifestar por meio de três formas básicas: (i) a constitucionalização simbólica voltada para a confirmação de certos valores sociais; (ii) a Constituição como instrumento de compromissos dilatórios; e (iii) a constitucionalização-álibi ${ }^{61}$.

A primeira hipótese de manifestação traduz a existência de dispositivos na Constituição que, sem importância normativo-jurídica, corroboram as crenças de determinados grupos ${ }^{62}$.

No entanto, Marcelo Neves ressalta que essa forma de manifestação não se refere à inviabilidade da concretização das normas constitucionais relativas aos direitos fundamentais, à separação de poderes, às eleições democráticas e à igualdade diante da lei. Trata-se de simbolismos específicos, "[...] de tal maneira que não cabe, a rigor, falar de constitucionalização simbólica" ${ }^{63}$.

Por sua vez, com base na análise da Constituição de Weimar de 1919 realizada por Carl Schmitt, Marcelo Neves explica a adoção de compromissos dilatórios no conteúdo da Constituição por meio das situações em que os indivíduos, ao recorrerem às suas disposições, não conseguem dela extrair uma interpretação jurídica convincente ${ }^{64}$.

Sendo assim, no âmbito da terceira hipótese de manifestação da constitucionalização simbólica, é necessário restringi-la "[...] aos casos em que a própria atividade constituinte (e reformadora), o Texto Constitucional e o discurso a ele referente funcionam, antes de tudo como álibi para os legisladores constitucionais e governantes" ${ }^{\prime \prime 6}$.

Isso significa ser necessário um entendimento da constitucionalização simbólica como um álibi em benefício dos agentes políticos dominantes e em detrimento da concretização da Lex Fundamentalis ${ }^{66}$.

Destarte, não deriva das "constituições simbólicas" qualquer modificação real no processo de poder. No mínimo, configura-se um adiantamento retórico da concretização do sistema constitucional para um futuro longínquo, como se tal concretização fosse viável sem modificações radicais nas relações de poder e na estrutura social ${ }^{67}$.

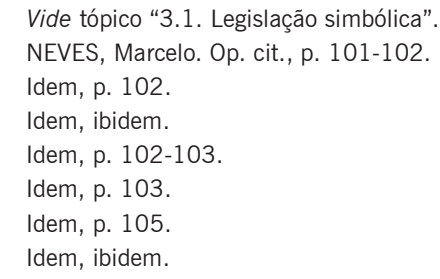




\subsubsection{Combate à hipertrofia da função simbólica dos direitos fundamentais}

Uma das contribuições do positivismo funcionalista para o direito consiste na afirmação do caráter simbólico das normas constitucionais que definem direitos fundamentais. Isso pelo fato de que a simples positivação de determinadas normas na Constituição, como a que estabelece a observância do princípio da dignidade da pessoa humana, representaria simbolizar a ideia de justiça de certa sociedade ${ }^{68}$.

No entanto, Ricardo Maurício Freire Soares constata que:

O crescimento desmesurado da função simbólica das normas referentes aos direitos fundamentais gera, frequentemente, a falsa sensação de realização de um direito justo, como se a dignidade da pessoa humana estivesse sendo assegurada concretamente pelo sistema jurídico, ainda que, no plano real das interações sociais, verifique-se o desrespeito constante à existência digna dos cidadãos. ${ }^{69}$

Especificamente quanto aos reflexos do princípio da legalidade administrativa no sistema normativo brasileiro, sua aplicação a partir de uma perspectiva tradicional faz com que os direitos fundamentais, positivados ou não na Constituição, sejam objeto de uma verdadeira constitucionalização simbólica.

Com efeito, tendo como premissa a ultrapassada crença na lei como instrumento eficaz para a solução dos problemas administrativos, os direitos fundamentais vêm sofrendo um processo de hipertrofia de sua função simbólica. Tanto é assim que, por diversas vezes, os sujeitos de direitos são levados a recorrer à tutela jurisdicional para a concretização de seus direitos fundamentais à saúde, educação, etc.

Ainda que não se fale em confirmação de valores sociais - como visto, uma das formas de manifestação do referido movimento - no que diz respeito a direitos fundamentais, a visão tradicional do princípio da legalidade administrativa implica a caracterização desses direitos como álibi para os administradores se desvencilharem da execução de competências constitucionais.

Nesse sentido, a preponderância do simbolismo nos direitos fundamentais, a partir, claro, da ótica da legalidade tradicional, faz com que o Estado seja qualificado como uma verdadeira instituição respeitável, vez que é detentor da competência constitucional para concretização dos aludidos direitos.

No entanto, a tão só atribuição dessa tarefa ao Estado não significa o seu efetivo cumprimento. Mesmo porque, seria necessária uma lei que determinasse ou autorizasse o agir administrativo. Assim, o Estado assumiria a qualidade de instituição promotora dos direitos fundamentais, merecedor, pois, da confiança

68 SOARES, Ricardo Maurício Freire. A releitura da teoria jusfundamental no direito constitucional brasileiro; NOVELINO, Marcelo (Coord.). Leituras complementares de direito constitucional: direitos humanos e direitos fundamentais. 4. ed. Salvador: JusPodivm, 2010. p. 141-160.

69 Idem, p. 154-155. 
pública, sem, entretanto, concretizá-los de maneira efetiva, vez que se encontra engessado pelo conteúdo tradicional do princípio da legalidade administrativa.

Com efeito, como antídoto a essa constitucionalização-álibi dos direitos fundamentais, é necessária uma mudança de perspectiva da legalidade administrativa, enxergando a Constituição como o diploma que vincula diretamente a atuação do administrador. Isso afasta os efeitos daquele movimento, vez que o Estado não precisa mais de uma lei, bastando uma competência constitucional para a concretização de direitos fundamentais - e para a sua atuação válida em geral.

Desse modo, o Estado, além de assumir a qualidade de instituição promotora dos direitos fundamentais, encontraria as condições para a sua efetivação, afastando a prevalência do simbolismo desses direitos. Isso se mostra mais viável quando se admite - de maneira correta - que o ente estatal pode fazer tudo o que não está proibido na lei, tendo em vista sua atuação vincular-se à Constituição e ao direito como um todo, o que confere a devida possibilidade de uma atuação eficaz do administrador.

A aludida constitucionalização-álibi, então, origina a falsa imagem de uma Administração Pública que responde aos problemas sociais invocando a sua qualidade de instituição que promove e concretiza direitos fundamentais, embora a solução desses problemas demande uma remodelagem de elementos tradicionais do regime jurídico-administrativo, dentre os quais o conteúdo do princípio da legalidade administrativa.

Destarte, esse movimento consiste em um mecanismo para a manipulação da sociedade, que tem o condão de imunizar o sistema político e a ordem jurídica administrativa contra outras alternativas, que não aquelas revestidas da concepção clássica, perpetuando, assim, o caráter tradicional e insuficiente do princípio da legalidade administrativa.

Ademais, é curioso observar uma diferente perspectiva da prevalência da função simbólica dos direitos fundamentais quando da sua análise em conjunto com a visão clássica do princípio da legalidade, no sentido de que esse movimento, a despeito da concretização da Constituição, serve como um verdadeiro álibi em favor dos agentes políticos dominantes.

Isso porque quando da inexistência de lei aplicável ao caso, não obstante haja competência constitucional para o administrador promover a concretização de certo direito fundamental, seu comportamento se orienta no sentido de invocar a ausência legal para assumir, perante os indivíduos, compromissos dilatórios, afastando a solução do problema para um futuro remoto, quando da existência de uma lei autorizando sua atuação.

Sendo assim, a Administração Pública se vale da prevalência do simbolismo daquele direito fundamental como um verdadeiro álibi para: (i) gerar um sentimento de bem-estar na sociedade, uma vez que seus indivíduos são trata- 
dos pela Constituição como sujeitos de direitos fundamentais; e (ii) procrastinar a concretização desses direitos para um futuro indeterminado, porquanto, à luz da visão tradicional da legalidade administrativa, inexistem condições legais para tal atuação.

Por outro lado, é importante perceber que esse movimento de constitucionalização-álibi costuma resultar na verdadeira descrença, por parte de toda a sociedade, nos próprios direitos fundamentais, vez que os problemas sociais não são efetivamente solucionados.

Em outras palavras, sujeitos de direitos fundamentais se veem à margem da proteção normativa face à hipertrofia do simbolismo dos direitos fundamentais, impulsionada, entre outros fatores, pelo conteúdo tradicional da legalidade administrativa, uma vez que, frise-se, restringe a atuação do Estado na concretização dos respectivos direitos.

Vale ressaltar que da prevalência do simbolismo nos direitos fundamentais não decorre nenhuma modificação real no processo de poder. Pelo contrário, tem-se a protelação de sua concretização para um futuro remoto, como se ela fosse possível sem transformações radicais nos elementos jurídicos.

Portanto, uma mudança de perspectiva da legalidade administrativa, de modo a vincular diretamente o administrador à Lex Fundamentalis e a todo o direito - e não apenas à lei - se mostra como um dos mecanismos propulsores das necessárias transformações radicais pelas quais deve passar o regime jurídico-administrativo, com o intuito de se realizar um efetivo combate à prevalência da função simbólica dos direitos fundamentais, garantindo, assim, a sua concretização pela Administração Pública.

\section{CONCLUSÃO}

O direito administrativo vem adotando posturas de questionamento de paradigmas clássicos. Assim, a Constituição e a teoria dos direitos fundamentais emergem como guias para a superação de suas categorias jurídicas tradicionais, dentre as quais o princípio da legalidade entendido como a total submissão do administrador às leis.

Essa mudança de perspectiva significa que os atos da administração, em havendo competência constitucional: (i) devem estar diretamente vinculados a todo o Direito, especialmente em conformidade com os princípios e regras da Lei Maior, diploma unificador de todo o sistema; e (ii) podem ser praticados quando não proibido pelas normas jurídicas.

Com o objetivo de construir uma maior legitimidade para a mudança da legalidade administrativa, utilizou-se a aplicação da teoria da legislação simbólica, que se refere à hipertrofia da função simbólica da atividade legiferante e da lei em detrimento de sua função jurídico-instrumental. 
Desse modo, o tradicional princípio da legalidade é alvo de um perigoso fortalecimento de seu simbolismo, que engessa o agir administrativo em nome de uma expectativa simbólica de que todas as ingerências pessoais, políticas e ideológicas do administrador serão afastadas pela lei. Entretanto, essas expectativas só serão devidamente satisfeitas nos casos em que haja uma vinculação direta da atuação estatal à Constituição.

Contudo, tanto simbolismo transparece para a sociedade uma crença de confiança nos sistemas político e jurídico, pois a visão tradicional da legalidade configuraria um escudo intransponível contra a subjetividade e o autoritarismo no agir administrativo. Mas a realidade vem demonstrando o fracasso da solução desses problemas por meio da legalidade estrita.

Não obstante, o conteúdo clássico da legalidade traduz um verdadeiro álibi da Administração Pública em face da sociedade. Por outro lado, sob a perspectiva instrumental, o problema do autoritarismo e da pessoalidade permanece fora do controle estatal.

A visão tradicional do princípio da legalidade administrativa implica a caracterização dos direitos fundamentais como álibi para os administradores se desvencilharem da execução de competências constitucionais, fazendo com o Estado seja qualificado como uma verdadeira instituição respeitável, vez que é detentor da competência constitucional para concretização dos aludidos direitos.

Isso origina a falsa imagem de uma Administração Pública que responde aos problemas sociais invocando a sua qualidade de instituição que promove direitos fundamentais, embora a solução desses problemas demande uma remodelagem do conteúdo do princípio da legalidade administrativa.

Quando da inexistência de lei aplicável ao caso, não obstante haja competência constitucional para o administrador promover a concretização de certo direito fundamental, seu comportamento se orienta no sentido de invocar a ausência legal para assumir, perante os indivíduos, compromissos dilatórios, afastando a solução do problema para um futuro remoto.

Com efeito, como antídoto a essa constitucionalização-álibi dos direitos fundamentais, é necessária uma mudança de perspectiva da legalidade administrativa, enxergando a Constituição como o diploma que vincula diretamente a atuação do administrador. Isso afasta os efeitos do aludido movimento, visto que o Estado não precisa mais de uma lei, bastando uma competência constitucional para a concretização de direitos fundamentais.

\section{REFERÊNCIAS}

BARROSO, Luis Roberto. Neoconstitucionalismo e constitucionalização do direito: o triunfo tardio do direito constitucional no Brasil. Revista da Escola Nacional da Magistratura, Brasília, n. 2, p. 26-72, out. 2006. 
BINENBOJM, Gustavo. A constitucionalização do direito administrativo no Brasil: um inventário de avanços e retrocessos. Revista Eletrônica sobre a Reforma do Estado (RERE), Salvador: Instituto Brasileiro de Direito Público, n. 13, mar./abr./maio 2008. Disponível em: <http://www.direitodoestado.com.br/rere.asp>. Acesso em: 3 ago. 2012.

BITTAR, Eduardo Carlos Bianca. O direito na pós-modernidade. Revista Sequência, n. 57, p. 131-152, dez. 2008.

CARVALHO FILHO, José dos Santos. Manual de direito administrativo. 25. ed. São Paulo: Atlas, 2012.

FURTADO, Lucas Rocha. Curso de direito administrativo. 3. ed. Belo Horizonte: Fórum, 2012.

JUSTEN FILHO, Marçal. Curso de direito administrativo. 7. ed. Belo Horizonte: Fórum, 2011.

MELLO, Celso Antônio Bandeira de. Curso de direito administrativo. 27. ed. São Paulo: Malheiros, 2010.

MOTTA, Carlos Pinto Coelho. Curso prático de direito administrativo. 3. ed. Belo Horizonte, 2011.

NEVES, Marcelo. A constitucionalização simbólica. 3. ed. São Paulo: WMF Martins Fontes, 2011

NOVELINO, Marcelo (Coord.). Leituras complementares de direito constitucional: direitos humanos e direitos fundamentais. 4. ed. Salvador: JusPodivm, 2010. 